NASA Technical Memorandum 103195

AIAA-90-1955

\title{
Effect of Vane Twist on the Performance of Dome Swirlers for Gas Turbine Airblast Atomizers
}

Gerald J. Micklow and Anju S. Dogra

University of Florida

Gainesville, Florida

and

H. Lee Nguyen

Lewis Research Center

Cleveland, Ohio

Prepared for the

26th Joint Propulsion Conference

cosponsored by the AIAA, SAE, ASME, and ASEE

Orlando, Florida, July 16-18, 1990

\section{N/SA}

(NASA-TM-103195) EFFFCT OF VANE TWIST TN

$N 90-2 \overline{5289}$

THE PERFORMANCE UF DUME SWIRLERS FUR GAS

TURAINE AIRPLAST ATOMILERS (NASA) $15 \mathrm{P}$

CSCL 200 
T- 


\title{
EFFECT OF VANE TWIST ON THE PERFORMANCE OF DOME SWIRLERS
}

FOR GAS TURBINE AIRBLAST ATOMIZERS

\author{
Gerald J. Micklow* and Anju S. Dogra† \\ University of Florida \\ Gainesville, Florida 32601 \\ and \\ H. Lee Nguyen \\ National Aeronautics and Space Administration \\ Lew is Research Center \\ Cleveland, Ohio 44135
}

\section{SUMMARY}

For advanced gas turbine engines, two combustor systems, the lean premixed/prevaporized (LPP) and the rich burn/quick quench/lean burn (RQL) offer great potential for reducing $\mathrm{NO}_{\mathrm{x}}$ emissions. An important consideration for either concept is the development of an advanced fuel injection system that will provide a stable, efficient, and very uniform combustion system over a wide operating range. High-shear airblast fuel injectors for gas turbine combustors have exhibited superior atomization and mixing compared with pressureatomizing fuel injectors. This improved mixing has lowered $\mathrm{NO}_{\mathrm{x}}$ emissions and the pattern factor, and has enabled combustors to accommodate alternate fuels while maintaining a stable, efficient combustion system. The performance of high-shear airblast fuel injectors is highly dependent on the design of the dome swirl vanes. The type of swirl vanes most widely used in gas turbine combustors are usually flat for ease of manufacture, but vanes with curvature will, in general, give superior aerodynamic performance. This study investigates the design and performance of high-turning, low-loss curved dome swirl vanes with twist along the span. The twist induces a secondary vortex flow pattern which will improve the atomization of the fuel, thereby producing a more uniform fuel-air distribution. This uniform distribution will increase combustion efficiency while lowering $\mathrm{NO}_{\mathrm{x}}$ emissions.

A systematic swirl vane design system is presented based on one-, two-, and three-dimensional flowfield calculations, with variations in vane turning angle, rate of turning, vane solidity, and vane twist as design parameters.

\section{INTRODUCT ION}

Emissions of advanced gas turbine engines have been the subject of many studies and programs. Of particular importance are the oxides of nitrogen $\left(\mathrm{NO}_{\mathrm{X}}\right)$ which are produced in advanced-cycle engines that operate at high pressures and temperatures. The $\mathrm{NO}_{\mathrm{x}}$ production can be reduced to environmentally

*Assistant Professor, Mechanical Engineering Department, Director, Computational Fluid Dynamics Laboratory, Member AIAA.

tGraduate Research Assistant, Mechanical Engineering Department.

¥Senior Research Engineer, Combustion Technology Branch, Member AIAA. 
acceptable levels only by designing advanced, low-emission combustors. Two promising concepts for reducing $\mathrm{NO}_{\mathrm{x}}$ emissions of advanced engines are the lean premixed/prevaporized (LPP) and the rich burn/quick quench/lean burn (RQL) combustor systems. Both systems reduce $\mathrm{NO}_{\mathrm{x}}$ formation by reducing flame temperature and the high-temperature residence time for the reacted products. The LPP combustor premixes fuel and air upstream of the combustion zone. Reduced $\mathrm{NO}_{\mathrm{X}}$ levels result since the fuel-air ratio is only in the range of 0.6 stoichiometric. This combustor system has a narrow range of operation, however, because of the possibility of preignition and flashback upstream of the combustor, and it can experience lean blowout during rapid deceleration and al titude relight.

The RQL concept incorporates staged burning. Combustion is initiated in a fuel-rich zone with an equivalence ratio in the range of 1.2 to 1.8. The hydrocarbon reactions proceed rapidly, depleting the available oxygen, thereby inhibiting $\mathrm{NO}_{\mathrm{x}}$ formation. Additional ai $r$ is then added, and combustion is completed under excess air conditions. The RQL concept offers wide stability limits and range of operation since flame flashbacks and lean blowout are eliminated.

For RQL combustion to be effective and environmentally acceptable, the fuel must be atomized well. If good atomization is not obtained, nonuniform burning will occur. Localized hot spots at near-stoichiometric conditions cause the highest temperatures and produce the greatest amount of $\mathrm{NO}_{\mathrm{X}}$. Reducing the $\mathrm{NO}_{\mathrm{x}}$ emissions by reducing the reaction temperature could adversely af fect the combustion stability and could increase emissions of carbon monoxide ( $\mathrm{CO}$ ) and unburned hydrocarbons, especially at low-power operation (ref. 1). Therefore a means of controlling the reaction zone stoichiometry over the entire operating range is required to minimize $\mathrm{NO}_{x}$ production while maintaining good combustor efficiency. Uniform fuel injection and mixing are essential for achieving these conditions.

Soot formation is also associated with poor fuel atomization. Soot is not an equilibrium product of combustion, and therefore its formation is influenced as much by the physical processes of atomization, evaporation, and fuel-air mixing as by reaction kinematics. Soot is generally produced anywhere that fuel-air mixing is inadequate. Problems of concern associated with soot formation are higher liner temperatures due to increased radiative heat transfer, impingement of carbon on metal surfaces resulting in erosion and reduced equipment lifetimes, and distortion of fuel spray distribution because of carbon deposits, leading to hot spots and increased $\mathrm{NO}_{\mathbf{x}}$ formation.

The superior combustion and reduced emissions of the high-shear airblast fuel injector relative to the conventional pressure atomizer is well established (ref. 2). This superior performance has led to the widespread adoption of the airblast fuel injector in modern high-pressure-ratio gas turbine engines. The airblast fuel injector produces a finer spray because of the thorough mixing of the fuel and air. This yields a flame of low luminosity and soot, thus resulting in relatively cooler liner walls, a minimum of exhaust smoke, and lower $\mathrm{NO}_{\mathrm{x}}$ emissions. Furthermore, the placement of the fuel droplets in the burning zone is mainly dictated by the airflow pattern, being almost insensitive to fuel flow variations. Thus airblast fuel injectors exhibit lower pat tern factors and therefore offer an important practical advantage in terms of turbine nozzle guide vane durability. 
Several authors have shown (refs. 3 to 6) that for low viscosity fluids the important parameters for decreasing fuel drop size are high air velocity and air density. Thus the swirl vanes should be designed to achieve a minimum loss of total pressure in the airflow passages and a high, uniform velocity profile at the vane exit. As a rough guide, a 1 percent reduction in combustor total pressure loss results in a 1 percent decrease in specific fuel consumption. In addition, the greatest exit velocity will occur when there is no total pressure drop. Any loss in total pressure will decrease the vane exit velocity, resulting in poorer atomization of the fuel. Furthermore, Beer et al. (ref. 7) show the importance of strong swirl or large turning in combustor swirl vane design. When the swirl intensity is increased in a jet, a point is reached when the adverse pressure gradient along the jet axis cannot be further overcome by the kinetic energy of the fluid particles flowing in the axial direction, and a recirculating flow is set up in the central portion of the jet between two stagnation points. This recirculation zone, which has the form of a toroidal vortex, plays an important role in flame stabilization since it constitutes a well-mixed zone of fuel, air, and combustion products. Test data of Kilik (ref. 8) show that the length of the recirculation region increases and that the reverse mass flow rate increases as vane turning increases. Furthermore, it was found that curved-vane swirlers produce a larger recirculation region than flat-vane swirlers with the same outlet angle and number of vanes. In addition, the swirl imparted to the flowfield by curved-vane swirlers was greater than for flat-vane designs. For small turning or swirl numbers this zone is much more limited.

For obtaining an effective and efficient airblast atomizer and correctly modeling the inlet flowfield required for computational studies of advanced combustors, the accurate prediction of the swirl vane flowfield is of paramount importance. Previously swirl vanes were typically designed by one-dimensional, incompressible methods with empirical loss correlations. The resulting swirl vane designs were flat-plate airfoils inclined at an angle to the incoming flow. At the exit, flat axial and circumferential velocity profiles had to be assumed, because of the one-dimensional analysis. Sander and Lilley (ref. 9) showed that the flat velocity profiles become progressively unrealistic as the swirl vane angle increases and that for large turning two- and three-dimensional effects cannot be neglected. Furthermore, flat swirl vanes of ten operate at stalled conditions with a high total pressure loss across the blade row which must be avoided for efficient engine operation. A one-dimensional analysis cannot accurately predict these flow phenomena. The wakes from the vane assembly operating under stalled conditions could drastically affect the quality of the atomization. Also a one-dimensional computation cannot make accurate assessments under the widely varying inlet conditions encountered by swirl vanes. Samuelson et al. show (ref. 10) that the inlet conditions can drastically change the swirl vane exit flowfield.

Before efficient, low-loss, high-turning, advanced swirl vane assemblies can be designed and the combustor flowfield can be accurately predicted, a more sophisticated vane analys is must be utilized. A systematic design analysis is presented here on the basis of one-, two-, and three-dimensional numerical techniques. A design of an advanced, low-loss, high-turning swirler is also presented. This system includes the effect of vane twist, which induces a secondary flow system to increase swirl and turbulence at the vane exit. This secondary flow will improve the atomization of the fuel. 


\section{THEORETICAL ANALYSIS}

Most theoretical analyses of swirler performance and numerical simulation of combustion flowfields have used simple, idealized swirler exit velocity profiles. Common assumptions have included flat axial and swirl velocity profiles with vanes of constant angle (refs, 11 to 14) and a flat axial profile with a linear swirl profile (solid body rotation) for swirlers with helicoidal vanes and for tangential-entry swirl generators (ref. 15). These assumptions, however, have been shown to be unrealistic (refs.9, 16, and 17) and to lead to considerable errors in numerical computations of the flowfield.

Therefore, for accurate modeling of the swirl vane flowfield, a more indepth analysis must be performed. A systematic design process has been developed for a low-loss, high-turning, advanced swirl vane assembly. This design process consists of three calculations of increasing complexity. First, a one-dimensional, isentropic, compressible flow analysis is performed to establish the basic design parameters. From known inlet conditions, the exit Mach number, static pressure drop, exit static temperature and swirl number are calculated over a range of vane turning. On the basis of these results, the vane outlet angle is selected from typical guidelines: maximum exit Mach number for flame stabilization, maximum static pressure drop for good combustor performance, and optimum swirl number to ensure strong swirl for good atomization of the fuel and a large recirculation zone downstream of the injector.

Second, the two-dimensional vane-to-vane flowfield is analyzed by using Micklow's two-dimensional, viscous-inviscid interaction procedure (ref. 18). The inviscid solution is obtained from a two-dimensional, compressible, secondorder-accurate finite-area full-potential cascade solver. The viscous solution is obtained from an implicit, two-dimensional, compressible, second-orderaccurate finite difference laminar or turbulent boundary layer routine. The calculation is spatially marched along the vane surface and into the wake. Calculations can be made in the direct mode with the pressure gradient specified or in the inverse mode with the "boundary layer mass flux" specified. Areas of strong interaction, such as those encountered in a region of flow separation or the vane trailing edge are easily handled when they are calculated in the inverse mode. The viscous-inviscid interaction is determined on the basis of updating the initial inviscid velocity distribution for displacement thickness effects by using thin airfoil theory. The required aerodynamic input for the two-dimensional analysis is obtained from the one-dimensional, compressible analysis for set vane turning. The required geometric inputs are the vane solidity and vane profile. The results from the two-dimensional analysis give the axial and circumferential velocity profiles at the vane exit for a fixed radius. From the viscous-inviscid analysis, the boundary layer growth along the vane surface and the velocity profile into the wake can be calculated. From these results, the number of vanes and the vane profile can be chosen to avoid flow separation on the vane suction surface, thereby minimizing total pressure loss, while maximizing swirl, vane exit velocity and obtaining uniform exit velocity profiles with high turning.

The final step in the design process is the calculation of the full threedimensional inviscid flowfield. The analysis uses the inviscid numerical simulation of Celestina et al. (ref. 19). The numerical procedure is based on a 
time marching, finite volume formulation that solves the average passage equation system for multiblade row configurations. The analys is employs a fourstage Runge-Kutta integration scheme to march the equations forward in time to obtain a steady-state solution. To suppress odd-even node point decoupling, a blend of second- and fourth-order difference smoothing operators are used to provide artificial dissipation. This analysis shows that desirable threedimensional characteristics of the flowfield can be enhanced by twisting the vanes. These desirable characteristics include the generation of a secondaryflow vortex pattern to increase turbulence and improve fuel atomization. In addition, a radial velocity component can be induced to increase the size of the recirculation zone, thereby producing a more stable flame zone that will improve combustion efficiency and lower $\mathrm{NO}_{x}$ emissions.

\section{RESULTS}

From the study of Micklow and Nguyen (ref. 20) a baseline design was established to satisfy the criteria of low loss (no flow separation) and high turning with a minimum of nonuniformity in the vane exit velocity profiles. From this study, flow turning as high as $70^{\circ}$ was achieved without flow separation on the vane surface. On the basis of these results, low-loss vane profiles were selected for the current study. A typical profile is presented in figure 1. The baseline design was for a curved-vane dome swirler assembly with a constant $60^{\circ}$ flow turning angle from the hub to the tip. The swirl number for this system, which was calculated from the one-dimensional analysis, was 1.4. For this swirl number, a large recirculation zone is produced downstream of the injector, giving efficient and stable combustor performance. The swirl vane assembly consists of 22 vanes, with a vane gap-to-chord ratio of 0.265 and a hub-to-tip ratio of 0.722 . The gap-to-chord ratio was held constant by increasing the chord as the radius increased. This will minimize the nonuniformity of the vane exit velocity profiles (ref. 20). The inlet Mach number was 0.0681 with a static temperature of $781 \mathrm{~K}$ and a static pressure of $1.4 \mathrm{MPa}$. These are typical compressor exit conditions for an advanced-cycle engine.

Plots of the nondimensional axial velocity versus radial and circumferential location are presented in figures 2 and 3 . The velocity is nondimensionalized by the inlet velocity. Uniform velocity profiles in both the radial and circumferential direction are achieved for the high turning angle of $60^{\circ}$. The flow was predicted to remain attached for all locations. Plots of the nondimensional tangential velocity versus radial and circumferential locations are shown in figures 4 and 5 . Once again uniform profiles are obtained at all locations. These uniform velocity profiles are considered to be very important for obtaining good fuel atomization. Plots of the nondimensional radial velocity versus radial and circumferential location are shown in figures 6 and 7 . The radial velocity component is small, and the flow is essentially twodimensional for the constant-turning case. The curved-vane swirl assembly was clearly superior to the flat-vane assembly with an equivalent turning of $60^{\circ}$. The flat vane system was predicted to be operating in a highly stalled, highloss condition.

To further improve the atomization performance of the swirl vane system, a secondary flow system can be induced through three-dimensional ef fects. By twisting the vane (i.e., changing the flow turning as a function of the radius) a secondary vortex system can be induced. The swirler assembly with vane twist 
was optimized to produce a strong secondary flow pattern. The flow turning angle was varied from $40^{\circ}$ at the hub to $70^{\circ}$ at the tip. The flow was predicted to remain attached at all locations. Plots of axial velocity versus radial and circumferential location are found in figures 8 and 9 . The profiles are uniform, even for the tip location where $70^{\circ}$ of turning is achieved. Note that the largest velocity is found at the hub. This will improve the fuel atomization where the fuel concentration and droplet size are the highest. The nondimensional tangential velocity profiles are presented in figures 10 and 11 . The profiles are uniform. The variation in swirl number based on a one-dimensional calculation is from 0.7 at the hub to 2.2 at the tip. The radial velocity profiles versus radial and circumferential location are shown in figures 12 and 13. A pronounced three-dimensional effect is evident. The maximum radial velocity is approximately 15 percent of the inlet velocity. This is more than three times the maximum radial velocity of the baseline design with constant turning. Figure 12 shows that the radial velocity is positive on the vane suction surface, negative on the pressure surface, and close to zero in the midgap region, creating a pair of counter-rotating vortices at the vane exit in the direction of the flow. This phenomenon is more clearly seen in figure 14. The average exit velocity has been subtracted from the velocity in the exit plane, leaving a perturbation velocity. Figure 14 clearly shows a pair of counter-rotating vortices in the exit plane. These vortices should increase the turbulence in the vane exit plane and enhance the fuel-air mixing. A further comparison between the baseline design with constant turning and the swirl vane assembly with twist is shown in figures 15 and 16 . Here, the secondary swirl number contours in the vane exit plane are presented. The secondary swirl number is defined as the dot product of the vorticity with the velocity vector divided by the dynamic head (density times the velocity squared). The secondary swirl for the swirl vane assembly with twist covers much more of the exit flow passage and is approximately two times as large. Figure 17 shows a full, three-dimensional swirl-vane-assembly Mach number contour plot. The large acceleration through the vane passage is clearly evident, and the exit Mach number is uniform for good fuel atomization.

\section{CONCLUSIONS AND RECOMMENDATIONS}

A systematic design procedure of advanced fuel-injector dome swirl vane assemblies based on one-, two-, and three-dimensional calculations has been presented. Two low-loss, high-turning swirl vane designs are presented. These two designs are clearly superior to flat vanes operating under stalled conditions. Incorporation of vane twist into the design (i.e., a variation in $f$ low turning and vane profile with radius) produces a secondary flow pattern. A pair of counter-rotating vortices created in the vane exit plane will enhance fuel-air mixing and improve combustor performance.

However, to further reduce total pressure loss and nonuniformities in the exit velocity, vane thickness distributions should be investigated to achieve a superior aerodynamic profile over curved zero-thickness vanes. The effects of the vane exit velocity profile on fuel atomization and combustor performance are currently being investigated. The velocity profiles are used as input for a full, three-dimensional Navier-Stokes solver with finite rate chemistry. This program has the capability of handling liquid sprays. 


\section{ACKNOWLEDGMENTS}

Appreciation is expressed to NASA Lewis Research Center for financial support for this study. The program, within the Combustion Technology branch, is associated with advanced cycle combustor design for $\mathrm{NO}_{\mathrm{x}}$ reduction in the High Speed Civil Transport engine.

\section{REFERENCES}

1. Rizk, N.K.; and Mongia, H.C.: Ultra-Low NO ${ }_{x}$ Rich-Lean Combustion. ASME Paper 90-GT-87, 1990.

2. Narster, E.R.; and Lefebvre, A.H.: Effect of Fuel Injector Method on Gas Turbine Combustion. Emissions from Continuous Combustion Systems, W. Correlius and W.G. Agnew, eds., Plenum Press, 1972, pp. 255-278.

3. Rizkalla, A.A.; and Lefebvre, A.H.: The Influence of Air and Liquid Properties on Airblast Atomization. J. Fluids Eng., vol. 97, no. 3, Sept. 1975 , pp. 316-320.

4. Mayer, E.: Theory of Liquid Atomization in High Velocity Gas Streams. Am. ?ocket Soc. J., vol. 31, no. 12, Dec. 1961, pp. 1783-1785.

5. Kim, K.Y.; and Marshall, W.R.: Drop Size Distributions from Pneumatic Atomizers. AIChE J., vol. 17, no. 4, July 1971, pp. 575-584.

6. Lefebvre, A.H.: Airblast Atomization. Prog. Energy Combust. Sci., vol. 6, 1980, pp. 233-261.

7. Beer, J.M.; and Chigier, N.A.: Combustion Aerodynamics. John Wiley and Sons, 1972 .

8. Kilik, E.: Better Swirl Generation by Using Curved Vane Swirlers. AIAA Paper 85-0187, Jan. 1985.

9. Sander, G.F.; and Lilley, D.G.: The Performance of an Annular Vane Swirler to Aid in Modeling Gas Turbine Combustor Flowfields and Swirling Confined Flow Turbulence. AIAA Paper 83-1326, June 1983.

10. Samuelsen, G.S., et al.: The Effect of Inlet Conditions on the Performance and Flowfield Structure of a Non-Premixed Swirl Stabilized Distribution Reaction. Symposium (International) on Combustion, 21st, Proceedings, The Combustion Institute, Pittsburgh, PA, 1986, pp. 1455-1461.

11. Rhode, D.L.; Lilley, D.G.; and McLaughlin, D.L.: On the Prediction of Swirling Flowfields Found in Axisymmetric Combustor Geometries. J. Fluids Eng., vol. 104, no. 3, Sept. 1982, pp. 378-384.

12. Rhode, D.L.; Lilley, D.G.; and McLaughlin, D.K.: Mean Flowfields in Axisymmetric Combustor Geometries with Swirl. AIAA J., vol. 21, no. 4, Apr. 1983 , pp. 593-600. 
13. Kerr, N.M.; and Fraser, D.: Swirl Part I: Effect on Axisymmetrical Turbulent Jets. J. Inst. Fuel, vol. 38, Dec. 1965, pp. 519-526.

14. Mathur, M.L.; and MacCallum, N.R.L.: Swirling Air Jets Issuing from Vane Swirlers, Part I: Free Jets; Part II: Enclosed Jets: J. Inst. Fuel, vol. 40, May 1967, pp. 214-245.

15. Chigier, N.A.; and Chervinsky, A.: Experimental Investigation of Swirling Vortex Motion in Jets. J. Appl. Mech., vol. 34, no. 2, June 1967, pp. 443-451.

16. Sander, G.F.: Axial Vane-Type Swirler Performance Characteristics. M.S. Thesis, School of Mechanical and Aerospace Engineering, Oklahoma State Univ., 1983. (Also, NASA CR-172995, 1983).

17. Beltagui, S.A.; and MacCallum, N.R.L.: Aerodynamics of Vane Swirled Flames in Furnaces. J. Inst. Fuel, vol. 49, Dec. 1976, pp. 183-193.

18. Micklow, G.J.: Viscous-Inviscid Interaction Method for Calculating the Flow in Compressor Cascade Blade Passages and Wake with Separation. AIAA Paper 90-2124, July 1990.

19. Celestina, M.L.; Mulac, R.A.; and Adamczyk, J.J.: A Numerical Simulation of the Inviscid Flow Through a Counterrotating Propeller. ASME Trans. J. Turbomach., vol. 108, 0ct. 1986, pp. 187-193. (Also ASME Paper 86-GF138, Oct. 1986).

20. Micklow, G.J.; and Nguyen, H.L.: The Design and Performance of Dome Swirlers for Gas Turbine Airblade Atomizers. Paper 89-38, 1989 Fall Meeting, Western States Section, The Combustion Institute. 


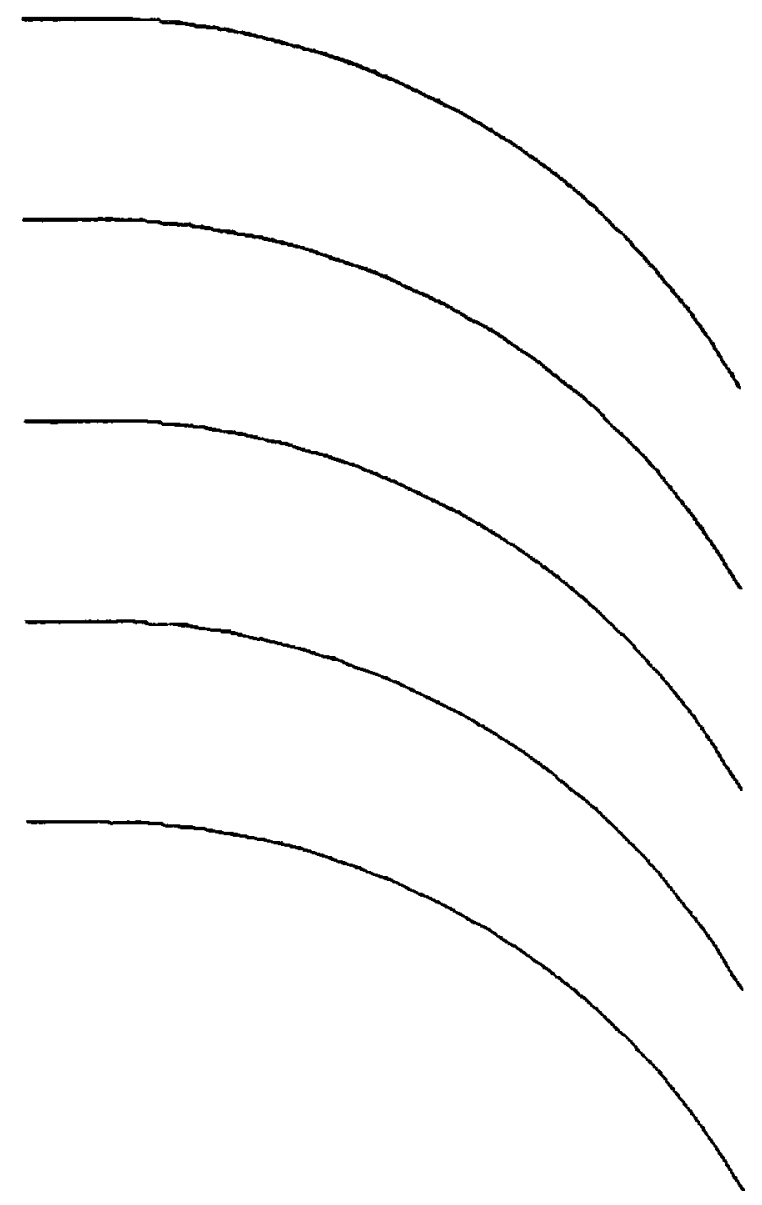

FIGURE 1. - VANE PROFILE OF SWIRL VAME ASSEMBLY.

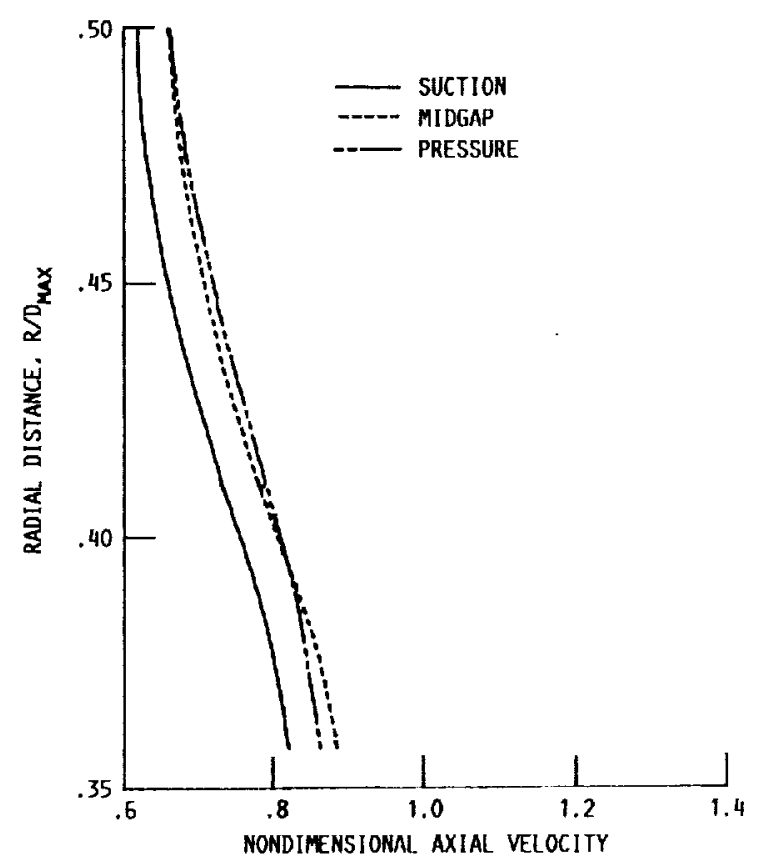

FIGURE 2. - SWIRL VANE EXIT AXIAL VELOCITY FROFILES FOR BASELINE DESIGN (CONSTANT TURNING) RADIAL DISTANCE VERSUS AXIAL VELOCITY.

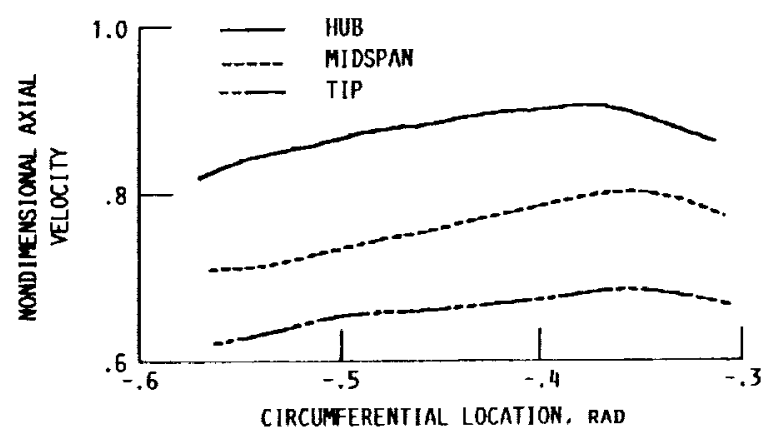

FIGURE 3. - SHIRL VAHE EXIT AXIAL VELOCITY PRDFILES FOR BASELINE DESIGN (CONSTANT TURNING); CIRCUMFERENTIAL DISTANCE VERSUS AXIAL VELOCITY. 


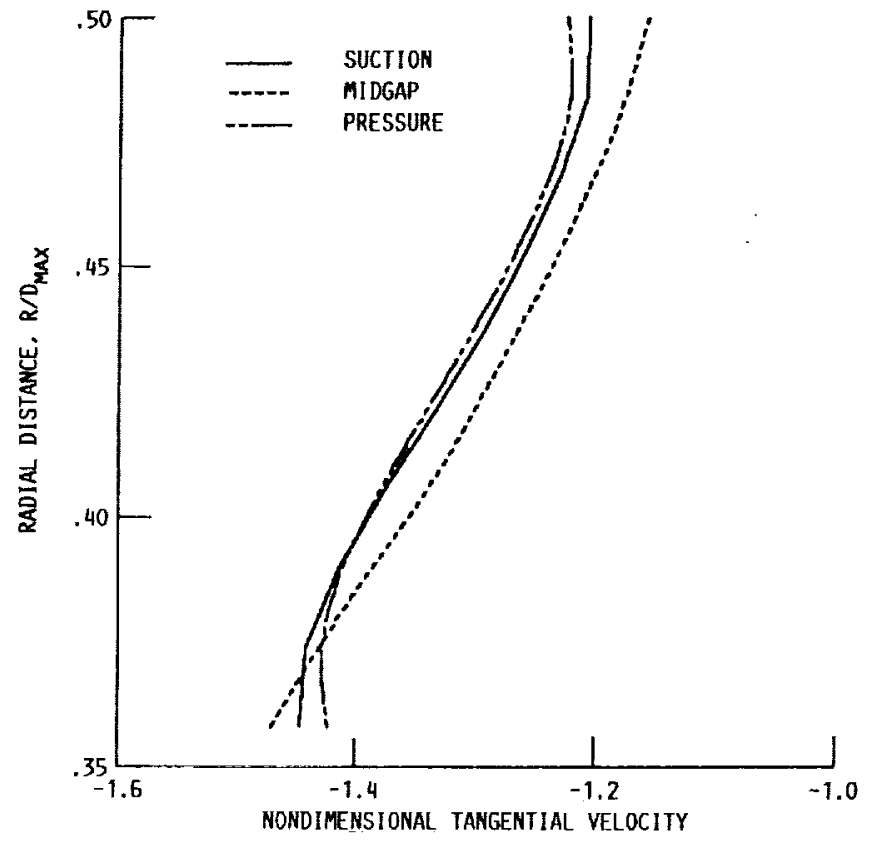

FIGURE 4. - SWIRL VANE EXIT TANGENIIAL VELOCITY PROFILES FOR BASELINE DESIGN (CONSTANT TURNING): RADIAL DISTANCE VERSUS TANGENTIAL VELOCITY.

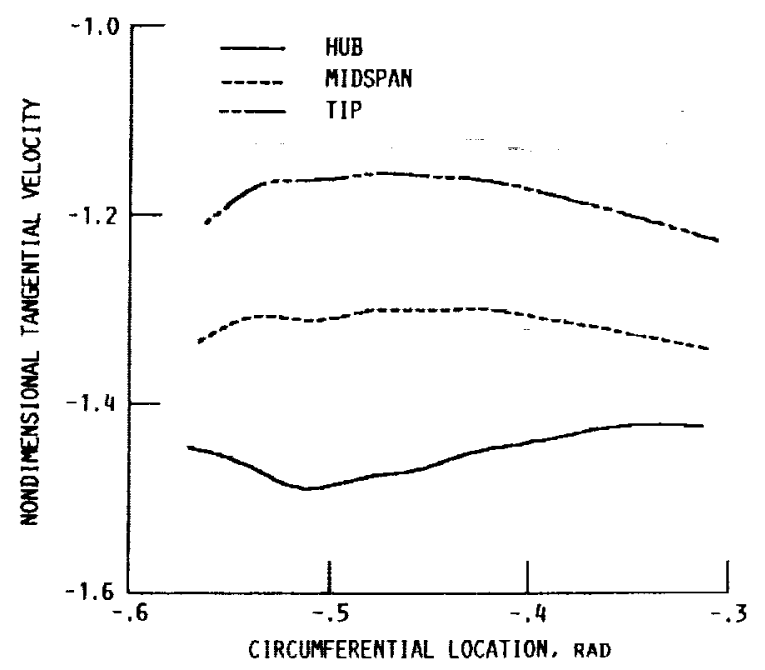

FIGURE 5. - SWIRL VANE EXIT TANGENTIAL VELOCITY PROFILES FOR BASELIME DESIGN (CONSTANT TURNING); CIRCUMFERENTIAL DISTANCE VERSUS TANGENTIAL VELOCITY.

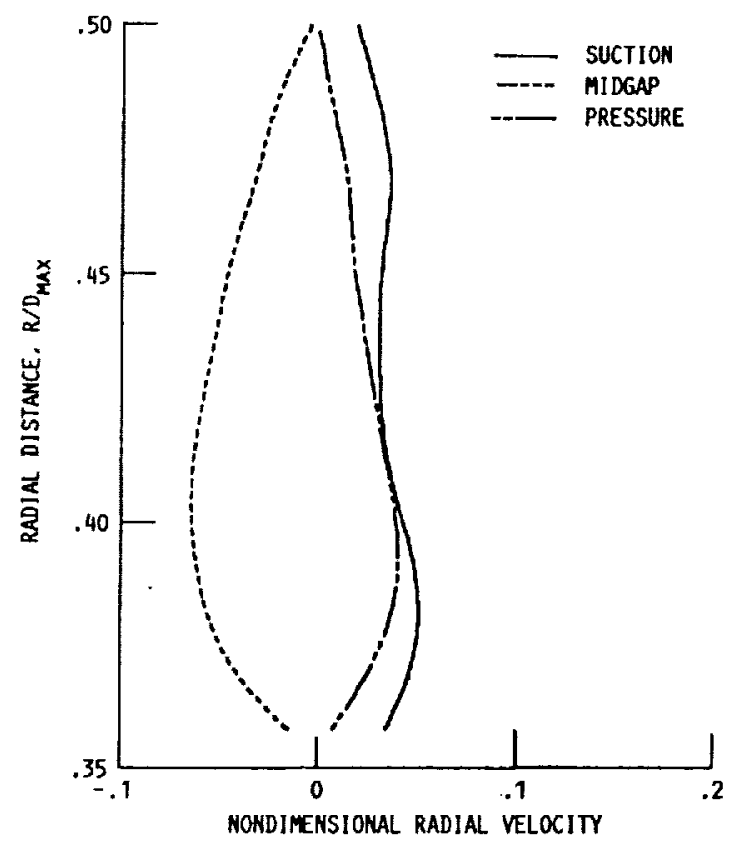

FIGURE 6. - SWIRL VAME EXIT RADIAL VELOCITY PROFILES FOR BASELIME DESIGN (CONSTANT TURNING): RADIAL DISTANCE VERSUS RADIAL VELOCITY.

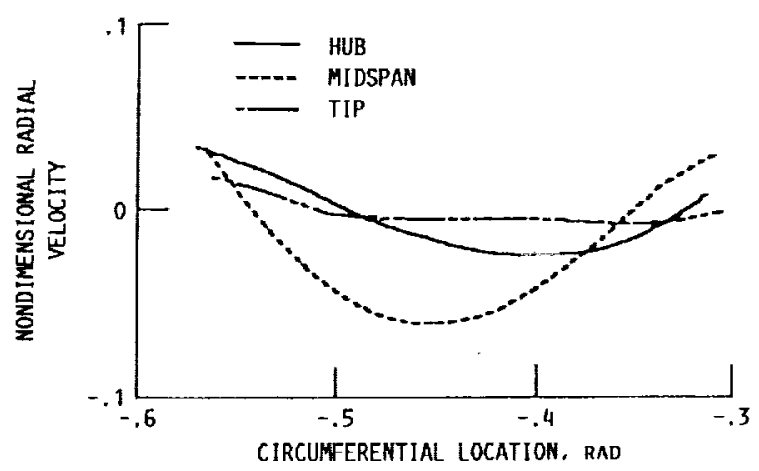

FIGURE 7. - SHIRL VANE EXIT RADIAL VELOCITY PROFILES FOR BASELINE DESIGN (CONSTANT TURNING): CIRCUMFERENTIAL DISTANCE VERSUS RADIAL VELOCITY. 


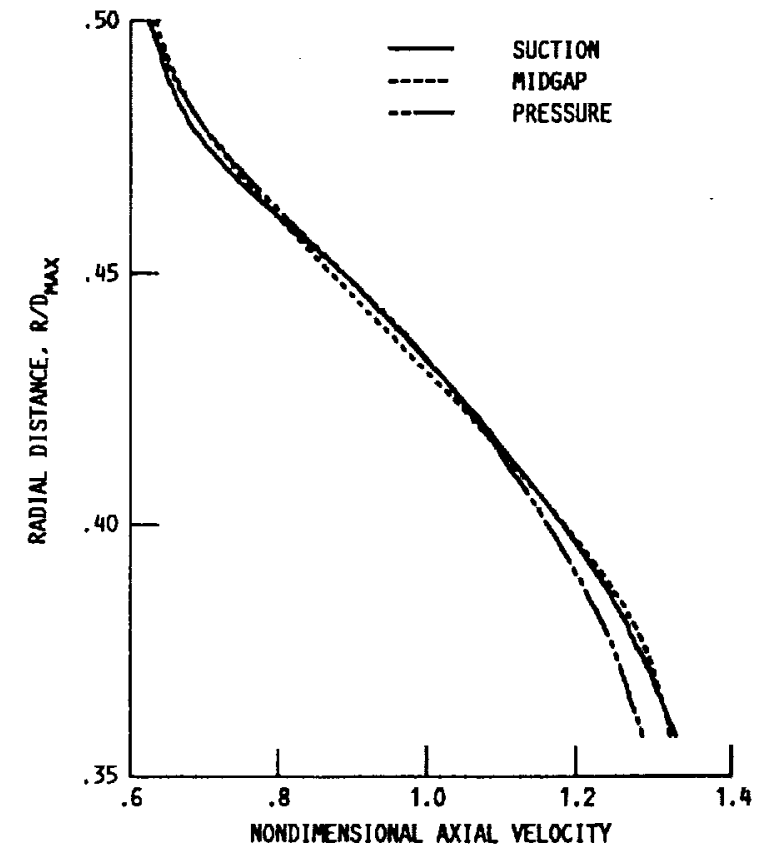

FIGURE 8. - SMIRL VANE EXIT AXIAL VELOCITY PROFILES FOR SWIRL VANE ASSEMBLY WITH TMIST; RADIAL DISTAMCE VERSUS AXIAL VELOCITY.

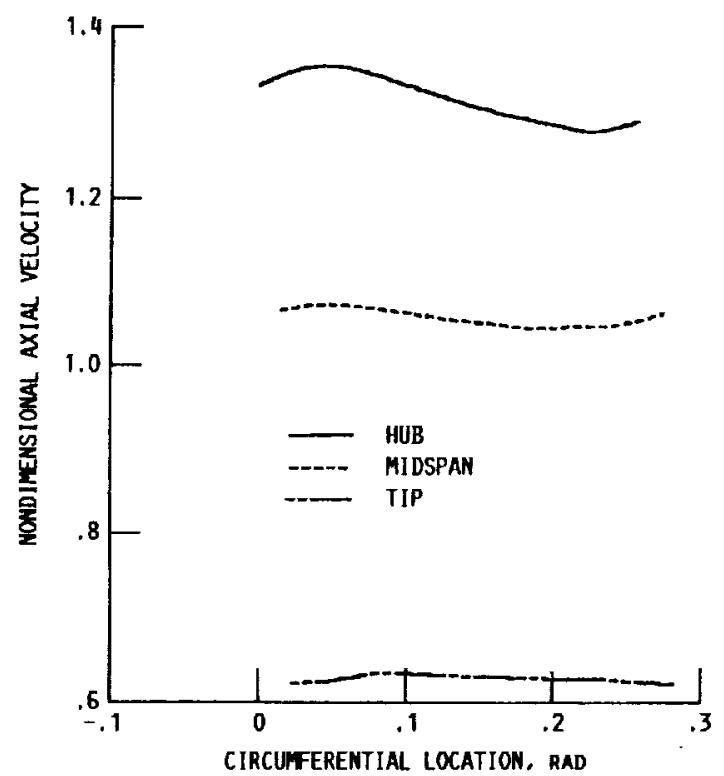

FIGURE 9. - SWIRL VAME EXIT AXIAL VELOCITY PROFILES FOR SWIRL VANE ASSEMBLY WITH TWIST; CIRCUMFERENTIAL DISTANCE VERSUS AXIAL VELOCITY.

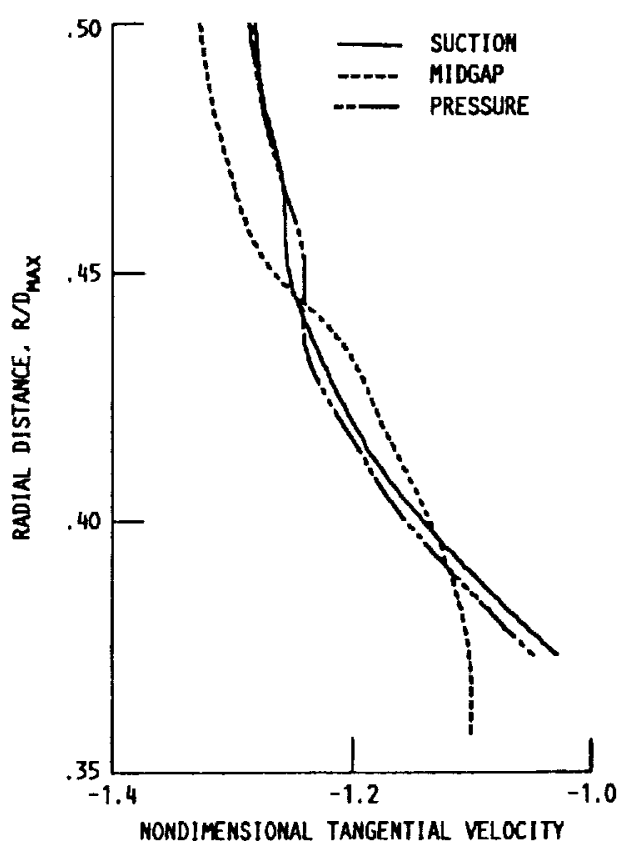

FIGURE 10. - SWIRL VAME EXIT TAMGENTIAL VELOCITY PROFILES FOR SWIRL VANE ASSEMBLY WITH THIST: RADIAL DISTANCE VERSUS TANGENTIAL VELOCITY.

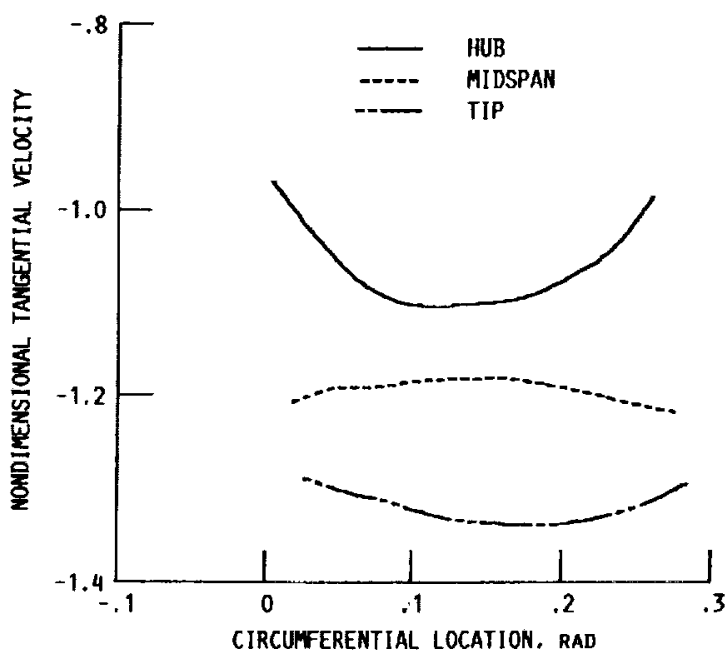

FIGURE 11. - SHIRL VANE EXIT TANGENTIAL VELOCITY PROFILES FOR SHIRL VANE ASSEMBLY WITH TWIST: CIRCUFFERENTIAL DISTANCE VERSUS TANGENTIAL VELOCITY. 


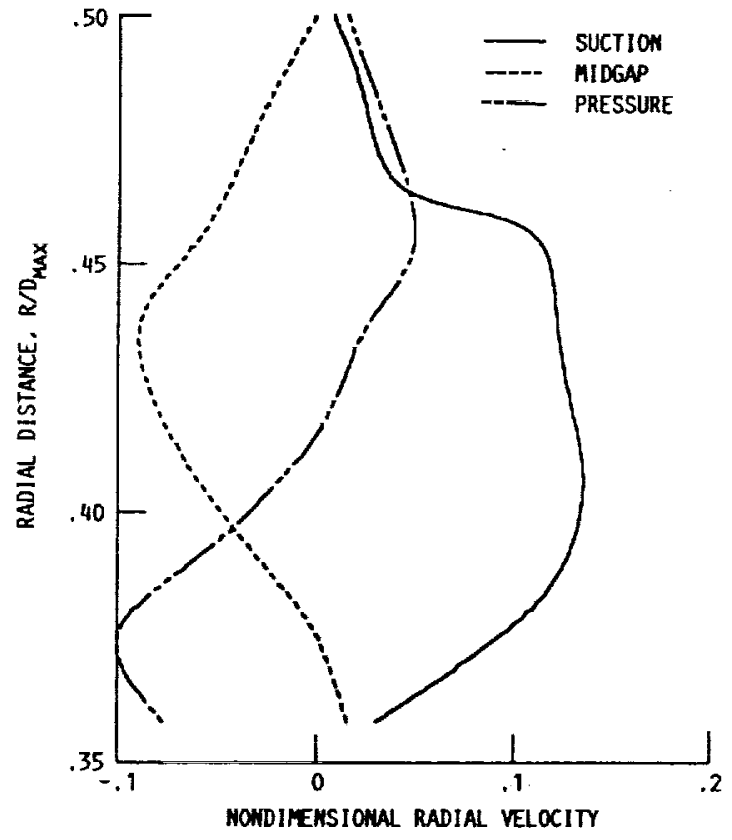

FIGURE 12. - SWIRL VANE EXIT RADIAL VELOCITY PROFILES FOR SMIRL VANE ASSEMBLY WITH TUIST; RADIAL DISTAKCE VERSUS RADIAL VELOCITY.

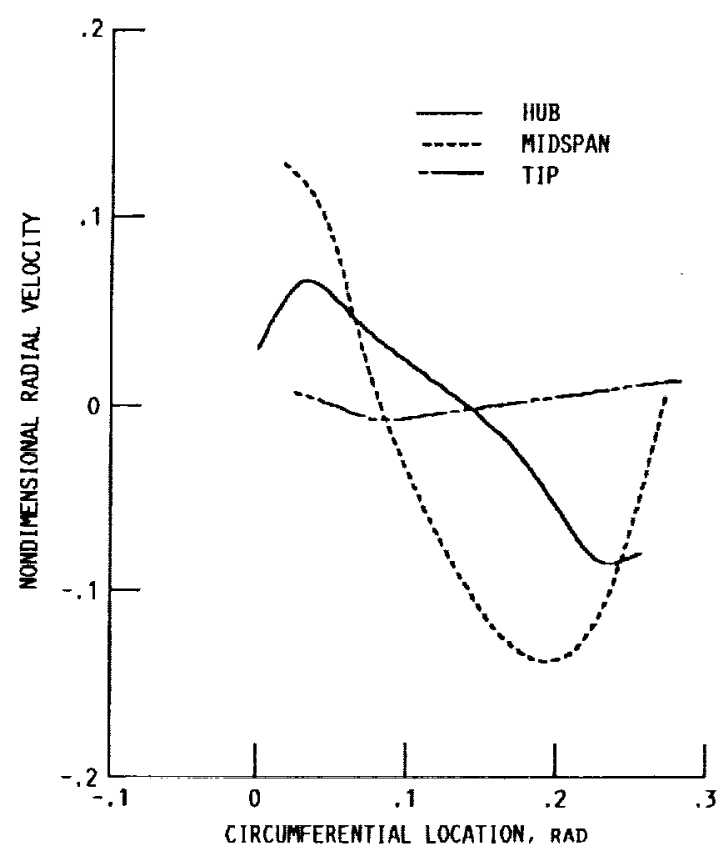

FIGURE 13. - SWIRL VANE EXIT RADIAL VELOCITY PROFILES FOR SWIRL VANE ASSEMBLY HITH TWIST: CIRCUMFERENTIAL, DISTANCE VERSUS RADIAL VELOCITY.

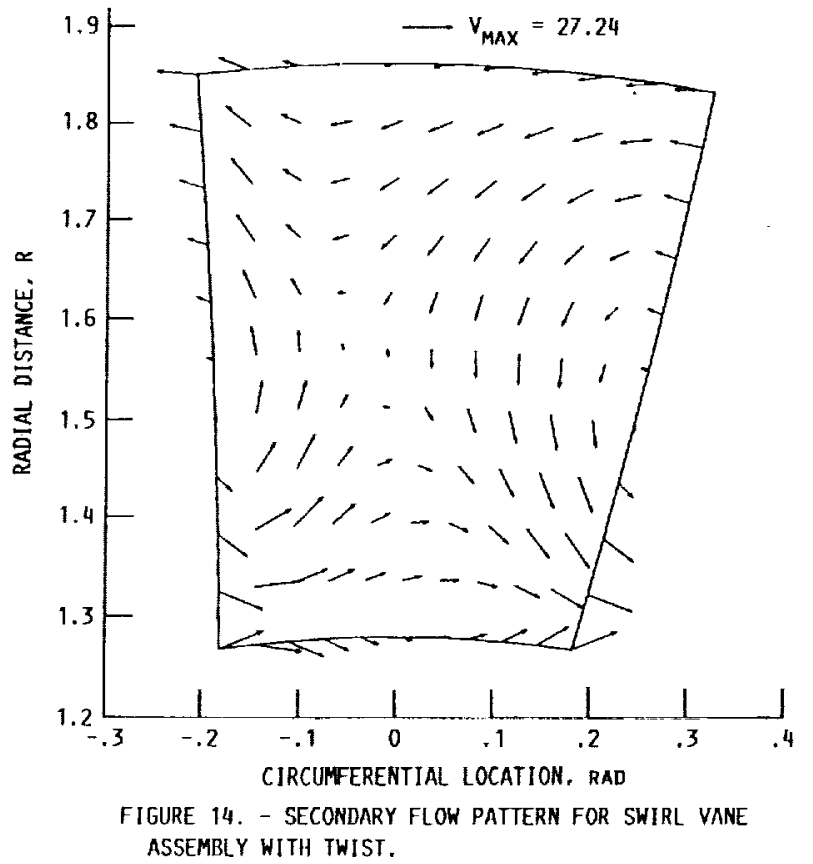

ASSEMBLY WITH TWISI. 


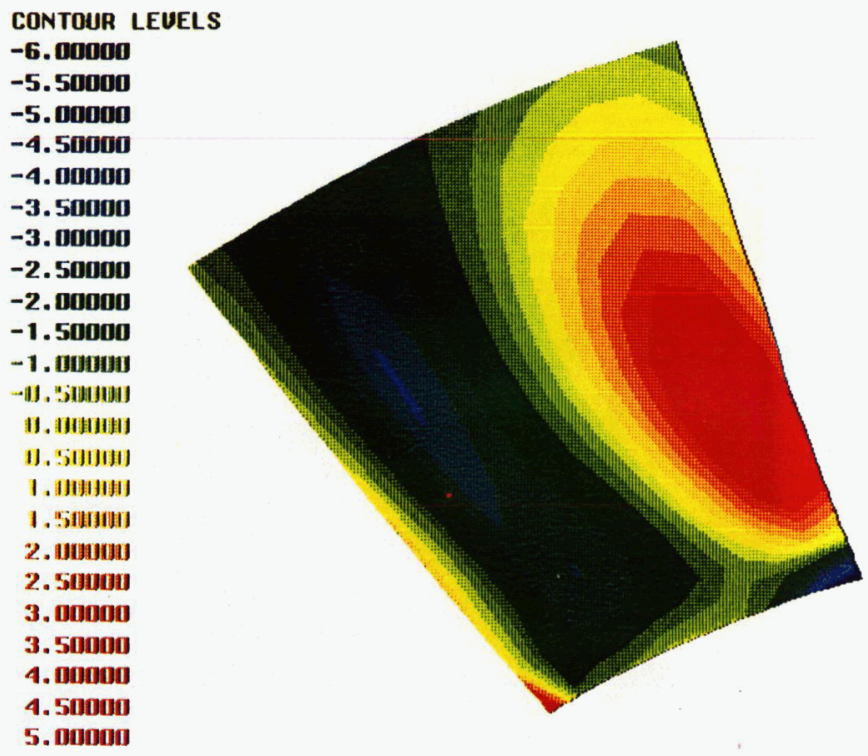

FIGURE 15. - SECONDARY SWIRL FOR SWIRL VANE ASSEMBLY WITH CONSTANT TURNING.

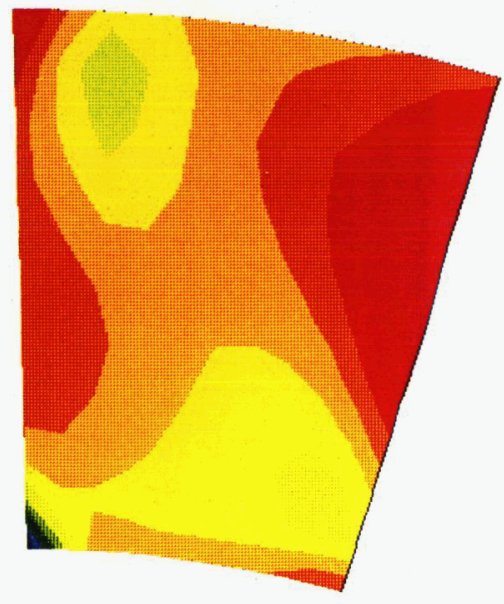

FIGURE 16. - SECONDARY SWIRL FOR SWIRL VANE ASSEMBLY WITH TWIST.

\subsection{0 \\ 0.05200 \\ 0.05400 \\ 0.05600 \\ I. 05800 \\ 0.06000 \\ 0. 06200 \\ ป. 06400 \\ I. 06600 \\ I. 06800 \\ 0.07000 \\ 0.07200 \\ 0.07410I \\ 0.07600 \\ ป. อ7หนบ

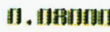 \\ Iง. และหมแ

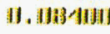 \\ II. IIsisilu \\ II. 11333131 \\ II. II:AU1। \\ II. Is:rena

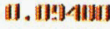

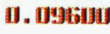 \\ ก. ก98mก \\ ป. 10000 \\ อ. 111201 \\ ข. 10400 \\ ป. 10600 \\ ป. 1080ก \\ ข. 11 10กI \\ ข. 11201}

CONTOUR LEUELS

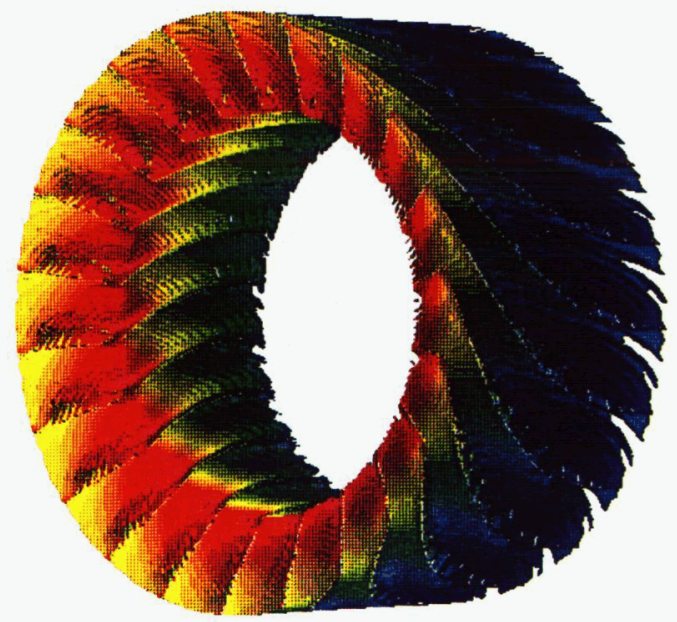

FIGURE 17. - MACH NUMBER CONTOURS FOR SWIRL VANE ASSEMBLY WITH TWIST. 



\begin{tabular}{|c|c|c|c|}
\hline \multicolumn{4}{|c|}{ Report Documentation Page } \\
\hline 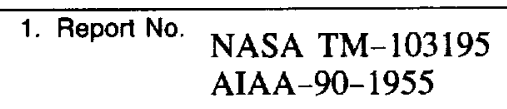 & 2. Government Accession No. & \multicolumn{2}{|c|}{ 3. Recipient's Catalog No. } \\
\hline \multicolumn{2}{|l|}{ 4. Title and Subtitle } & \multicolumn{2}{|l|}{ 5. Report Date } \\
\hline \multirow{2}{*}{\multicolumn{2}{|c|}{$\begin{array}{l}\text { Effect of Vane Twist on the Performance of Dome } \\
\text { Swirlers for Gas Turbine Airblast Atomizers }\end{array}$}} & & \\
\hline & & \multicolumn{2}{|c|}{ 6. Performing Organlzation Code } \\
\hline \multicolumn{2}{|c|}{$\begin{array}{l}\text { 7. Author(s) } \\
\text { Gerald J. Micklow, Anju S. Dogra, and H. Lee Nguyen }\end{array}$} & \multicolumn{2}{|c|}{$\begin{array}{l}\text { 8. Performing Organization Report No. } \\
\text { E-5589 }\end{array}$} \\
\hline . & & \multicolumn{2}{|l|}{$\begin{array}{l}\text { 10. Work Unit No. } \\
537-01-11\end{array}$} \\
\hline \multirow{2}{*}{\multicolumn{2}{|c|}{$\begin{array}{l}\text { 9. Performing Organization Name and Address } \\
\text { National Aeronautics and Space Administration } \\
\text { Lewis Research Center } \\
\text { Cleveland, Ohio 44135-3191 }\end{array}$}} & \multicolumn{2}{|c|}{ 11. Contract or Grant No. } \\
\hline & & \multirow{2}{*}{\multicolumn{2}{|c|}{$\begin{array}{l}\text { 13. Type of Report and Period Covered } \\
\text { Technical Memorandum }\end{array}$}} \\
\hline \multirow{2}{*}{\multicolumn{2}{|c|}{$\begin{array}{l}\text { 12. Sponsoring Agency Name and Address } \\
\text { National Aeronautics and Space Administration } \\
\text { Washington, D.C. 20546-0001 }\end{array}$}} & & \\
\hline & & \multicolumn{2}{|c|}{ 14. Sponsoring Agency Code } \\
\hline \multicolumn{4}{|c|}{$\begin{array}{l}\text { Prepared for the 26th Joint Propulsion Conference cosponsored by the AIAA, SAE, ASME, and ASEE, Orlando, } \\
\text { Florida, July 16-18, } 1990 \text {. Gerald J. Micklow and Anju S. Dogra, University of Florida, Gainesville, Florida 32601; } \\
\text { H. Lee Nguyen, NASA Lewis Research Center. }\end{array}$} \\
\hline \multicolumn{4}{|c|}{$\begin{array}{l}\text { For advanced gas turbine engines, two combustor systems, the lean premixed/prevaporized (LPP) and the rich } \\
\text { burn/quick quench/lean burn (RQL) offer great potential for reducing } \mathrm{NO}_{\mathrm{x}} \text { emissions. An important consideration } \\
\text { for either concept is the development of an advanced fuel injection system that will provide a stable, efficient, } \\
\text { and very uniform combustion system over a wide operating range. High-shear airblast fuel injectors for gas turbine } \\
\text { combustors have exhibited superior atomization and mixing compared with pressure-atomizing fuel injectors. This } \\
\text { improved mixing has lowered } \mathrm{NO}_{\mathrm{x}} \text { emissions and the pattern factor, and has enabled combustors to alternate fuels } \\
\text { while maintaining a stable, efficient combustion system. The performance of high-shear airblast fuel injectors is } \\
\text { highly dependent on the design of the dome swirl vanes. The type of swirl vanes most widely used in gas turbine } \\
\text { combustors are usually flat for ease of manufacture, but vanes with curvature will, in general, give superior } \\
\text { aerodynamic performance. This study investigates the design and performance of high-turning, low-loss curved } \\
\text { dome swirl vanes with twist along the span. The twist induces a secondary vortex flow pattern which will } \\
\text { improve the atomization of the fuel, thereby producing a more uniform fuel-air distribution. This uniform distri- } \\
\text { bution will increase combustion efficiency while lowering } \mathrm{NO}_{\mathrm{x}} \text { emissions. A systematic swirl vane design system } \\
\text { is presented based on one-, two-, and three-dimensional flowfield calculations, with variations in vane-turning } \\
\text { angle, rate of turning, vane solidity, and vane twist as design parameters. }\end{array}$} \\
\hline $\begin{array}{l}\text { 17. Key Words (Suggested by Author(s)) } \\
\text { Airblast atomizers } \\
\text { Dome swirlers } \\
\text { Vane twist }\end{array}$ & $\begin{array}{r}\text { 18. Distri } \\
\mathrm{U} \\
\mathrm{Su}\end{array}$ & $\begin{array}{l}\text {-Unlimited } \\
\text { gories } 34,05\end{array}$ & \\
\hline $\begin{array}{l}\text { 19. Security Classif. (of this report) } \\
\text { Unclassified }\end{array}$ & $\begin{array}{l}\text { 20. Security Classif. (of this page } \\
\text { Unclassified }\end{array}$ & \begin{tabular}{|c} 
21. No. of pages \\
14
\end{tabular} & \begin{tabular}{|lr} 
22. & Price* \\
. & $\mathrm{A03}$
\end{tabular} \\
\hline
\end{tabular}


